\title{
Beatriz Maria Alasia de Heredia: Conhecimento e política como compromissos
}

\section{Henyo T. Barretto Filho}

\section{(2) OpenEdition \\ 1 Journals}

Edição electrónica

URL: http://journals.openedition.org/aa/3543

DOI: 10.4000/aa.3543

ISSN: 2357-738X

\section{Editora}

Programa de Pós-Graduação em Antropologia Social (UnB)

\section{Edição impressa}

Data de publição: 1 junho 2019

Paginação: 373-378

ISSN: 0102-4302

\section{Refêrencia eletrónica}

Henyo T. Barretto Filho, «Beatriz Maria Alasia de Heredia: Conhecimento e política como

compromissos», Anuário Antropológico [Online], v.44 n.1 | 2019, posto online no dia 06 julho 2019, consultado o 28 abril 2021. URL: http://journals.openedition.org/aa/3543 ; DOI: https://doi.org/ 10.4000/aa.3543

\section{(c) (7) (9)}

Anuário Antropológico is licensed under a Creative Commons Atribuição-Uso Não-Comercial-Proibição de realização de Obras Derivadas 4.0 International. 


\title{
Beatriz Maria Alasia de Heredia: conhecimento e política como compromissos
}

\author{
Henyo Trindade Barretto Filho \\ Universidade de Brasília - Brasil
}

\begin{abstract}
O compromisso não está no tema.
Assim, não há temas nobres, em si;

a nobreza está no rigor dispensado ao tratamento, e na medida em que se está sempre discutindo o lugar de onde o antropólogo o trabalha.

O compromisso com a atitude de conhecimento foi o que fez com que os que assim pensamos tivéssemos - e eu, em determinados momentos de minha vida a possibilidade de vincular o compromisso social com o compromisso com o conhecimento, sem que este fosse desqualificado (Heredia, 2005a:96).
\end{abstract}

Assim como Beatriz Heredia decidiu trabalhar em Antropologia e iniciou sua vida profissional na Argentina a partir de uma experiência como assistente de pesquisa de um velho professor americano, foi ela a responsável direta por eu ter escolhido a Antropologia no longínquo ano de 1986 - o último da minha graduação em Ciências Sociais no IFCS/UFRJ. Este necrológio, portanto, não pode ter outro tom que o pessoal e afetivo, o da memória e reconhecimento pelos aprendizados compartilhados por essa pessoa luminosa e intensa com quem tive a oportunidade de conviver no período em que ela se consolidava como antropóloga brasileira - que coincidiu com meus "anos de formação".

Conheci Beatriz no primeiro semestre letivo de 1984 como professora da primeira disciplina obrigatória de teoria antropológica no currículo da graduação, ocasião na qual lemos integralmente $O s$ Nuer e quase todos os artigos de $A$ Interpretação das Culturas. Na ocasião, eu iniciava estudos de fotografia, sonhando emular Pierre Verger, e uma vez tentei capturar o magnetismo que Beatriz já exercia sobre nós em sala de aula - sem sucesso. À época, conforme soube pouco depois, ela ainda era doutoranda em Antropologia Social no Museu Nacional, sob a orientação 
do igualmente saudoso professor Castro Faria, e vivia permanentemente no Brasil há oito anos.

Beatriz já tinha uma significativa trajetória de vida no Brasil, pois veio para o Rio de Janeiro em 1971 cursar o mestrado no recém recém-instituído PPGAS do Museu Nacional, que concluiu em 1976, entre idas e vindas à Argentina e às zonas canavieiras de Alagoas e Pernambuco, onde fez seu trabalho de campo. Em seguida, em 1979, entrou por concurso no IFCS/UFRJ. Seu retorno em 1976, contudo, tornou-se definitivo, pois se deu dois dias antes do golpe que instituiu o terrorismo de estado na Argentina. Como ela narrou, quase 30 anos depois: "nos instalamos en Rio de Janeiro y, aunque entonces no lo sabia, ya en forma permanente” (Heredia, 2005b:5). Refugiando-se da ditadura em seu país de origem, Beatriz foi acolhida no grupo de pesquisa sobre campesinato do Museu, que se tornou sua segunda casa, e se (re)construiu como cidadã e acadêmica plenas no Brasil. Segundo ela mesma, em "una situación liminal, desde un área fronteriza pues, aunque argentina, soy una antropóloga brasileña. [...] El espacio en Argentina fue interrumpido, me fue una vez [1971] y tuve que irme después [1976]" (:2).

Em março de 1986, início do meu último ano letivo no IFCS, nos reencontramos um dia nas suas escadarias. Beatriz me cumprimentou, segurou-me pelo braço e interpelou-me: "Não vi o seu nome entre os candidatos à seleção de monitores de ensino de graduação. As inscrições se encerram hoje. Você vai agora na secretaria se inscrever, pois, se for selecionado, vai trabalhar comigo”. Ela foi tão categórica - um predicado muito seu, como discerni mais tarde - que eu nem pestanejei. Os detalhes desse processo seletivo renderiam uma história à parte. Cabe lembrar que as universidades também estavam se reconstruindo no país naquele momento. Se, por um lado, ainda tínhamos aulas com militares (Estudos de Problemas Brasileiros, por exemplo, era ministrada por um sargento do Exército) e havia olheiros na turma (como o Ari, que nunca escondeu isso de ninguém); por outro, oportunidades estavam começando a se (re)institucionalizar, como as bolsas de monitoria e de iniciação científica - que, pela primeira vez em anos, voltavam a ser oferecidas por meio de processos seletivos. Fato é que fomos três os selecionados para sermos monitores: eu de Beatriz, Sidnei Peres (hoje Professor Titular do ICHF/UFF) de Marie-France Garcia e Rogério Victer de Marco Antonio Mello. Em nossa primeira reunião de trabalho, ela sugeriu que nos apresentássemos a um grupo de pesquisa recém-formado no Museu Nacional que estava recrutando estagiários. Foi assim que Sidnei, Rogério e eu nos integramos ao Projeto Estudo sobre Terras Indígenas 
no Brasil (PETI), coordenado por João Pacheco de Oliveira e Antonio Carlos de Souza Lima.

Foi, portanto, no meu último ano de graduação, como seu monitor de ensino, que convivi com e pude conhecer melhor Beatriz. Ela estava concluindo sua tese de doutorado, que defendeu naquele ano e foi publicada em livro dois anos depois (Heredia, 1988) - que, ao autografar, me ofereceu "pelos encontros passados e futuros". Cheguei a assumir integralmente algumas aulas das disciplinas que ela ministrou em 1986, seja porque ela precisava se ausentar para se dedicar à tese, seja porque ela viajava para acompanhar os dissídios coletivos dos trabalhadores dos engenhos da região em que pesquisava. Beatriz também militava ativamente no movimento docente. Lembro da igualmente querida professora Maria das Graças Augusto, da Filosofia, comentar comigo sobre como Beatriz sempre se colocava de modo qualificado, coerente e incisivo nas assembleias da AdUFRJ, e que ela sempre esperava pela intervenção de Beatriz para se posicionar.

No convívio cotidiano com ela, entendi - e espero ter aprendido - o que era uma profissional comprometida, tanto com a atitude de conhecimento rigorosa, quanto com os direitos e o destino dos grupos com os quais trabalhamos - aprendizado que prossegui no PETI. Beatriz foi, para muitos da minha geração, um referencial de profissional antropóloga plena, e as oportunidades que ela generosamente abria para seus alunos me fizeram desviar da Ciência Política para a Antropologia. Tal como seus professores na Argentina e no Brasil haviam introduzido Beatriz "en un habitus y en una forma de cuestionamiento": "aprendimos el hábitus de hacer investigación haciéndola”, "que la investigación se enseña en la práctica” (Heredia, 2005b:7-8); com ela e os pesquisadores aos quais ela me apresentou, aprendi a valorizar "el modelo artesanal de investigación"(:8). Antropologia, para mim, era o que ela e essas pessoas encarnavam. Sua abertura e generosidade como docente, e a relação simétrica que tinha com monitores e alunos deixaram marcas indeléveis em todos que convivemos com ela.

Essa influência só fez se aprofundar, pois voltei a ser seu aluno no mestrado no Museu Nacional, em um memorável curso sobre sociedades camponesas que Beatriz e Moacir Palmeira - seu orientador no mestrado - ministraram no primeiro semestre letivo de 1988. Foi nesse curso que logramos entender o significado das obras do grupo de pesquisadores reunidos no Museu para a constituição dos estudos de campesinato no país, em especial os trabalhos de Beatriz: sobre o cálculo e a racionalidade econômicas do campesinato vinculado à plantation, e a 
família como unidade de produção e consumo, que levava a estudar o campesinato enquanto sistema econômico específico (a inspiração chayanoviana de $A$ Morada da Vida - Heredia, 1979); e sobre a complexidade dos distintos sistemas de dominação e a multiplicidade das relações de dominação - violenta, simbólica, em distintas escalas (expressa em Formas de Dominação e Espaço Social - Heredia, 1988).

Nos afastamos quando a vida me levou para Manaus, em 1990, e me trouxe para Brasília, em 1994, período este que coincide com a diversificação de interesses de pesquisa de Beatriz (destacando-se sua participação no Núcleo de Antropologia da Política, a extensa investigação sobre impactos dos assentamentos de reforma agrária no Brasil e as pesquisas "Sociedade e Economia do Agronegócio" com Moacir Palmeira e "Ambientalização de Conflitos Sociais" e "Movimentos Sociais e Esfera Pública”, com José Sérgio Leite Lopes - estas duas importantíssimas para o meu próprio trabalho) e com sua experiência profissional em consultorias e assessorias para diversos organismos internacionais, e em organizações da sociedade civil (como Diretora do Greenpeace para a América Latina, elaborando a política de trabalho e dirigindo os afazeres do conjunto de escritórios para toda a região) - sobre a qual ela escreveu um instigante texto (Heredia, 2005a). Ultimamente, Beatriz coordenava o Programa de Memória dos Movimentos Sociais (Memov) do Colégio Brasileiro de Altos Estudos da UFRJ, do qual foi vice-diretora. Ela fez tudo isso, mais recentemente, já lutando contra uma doença pulmonar obstrutiva crônica, que, salvo pelos períodos de internação, em momento algum pareceu ter reduzido a sua vitalidade.

Em seu período ongueiro, compartilhamos alguns momentos de ativismo e militância socioambiental nos bastidores do poder constituído em Brasília e em manifestações de organizações do movimento social e da sociedade civil. Lembro-me de um almoço em Brasília, num intervalo dessas atividades, quando eu, professor da UnB licenciado para o doutorado na FFLCH/USP, ouvi dela, com aquele sotaque e entonação característicos: “Aproveita rapaz. É o melhor período da nossa vida”. Tentei seguir este seu conselho e aqueles que ela dava sem saber, pela intensidade com que fazia tudo com o que se comprometia - compromisso que, segundo ela mesma, é uma categoria central para entender sua vida, trajetória e obra.

Como disse alguém, que já não lembro, em outra homenagem póstuma, Beatriz foi uma "mulher aguerrida e apaixonada pela antropologia e pelo Brasil". Quiçá tal paixão, intensidade e o fato de ter encontrado aqui sua outra casa expliquem o impacto que podem ter tido nela o resultado das eleições presidenciais de 2018 - 
com o prenúncio de um novo período autoritário - e o incêndio no Museu Nacional. Pouco mais de um mês depois, ela nos deixou.

Em maio de 2004, retornando à Universidade Nacional de Córdoba, onde se formou em História, em 1964, Beatriz proferiu, como homenageada, a conferência de abertura do VI Congresso Argentino de Antropologia Social. Na ocasião, ela se perguntou: “¿cómo mantener el rigor científico sin excluir el compromiso político?”; “¿cómo ser militante manteniendo al mismo tiempo el rigor científico?” (Heredia, 2005b:11). Não exageraria ao responder que Beatriz respondeu com sua própria vida a essas perguntas. Falando de sua trajetória, ela notou que, como tantos outros, nós "representamos a muchas otras personas, algunas de las cuales están acá con nosotros [...], y otros que aunque ya no están más entre nosotros, también formaron parte de ese mundo y hoy están presentes en el recuerdo y en su obra” (2005b:2-3). É desse modo que a trajetória de Beatriz, marcada pelo compromisso simultâneo com o rigor acadêmico e as lutas políticas na defesa de direitos, se faz hoje presença constante em nossas vidas.

Recebido: 09/02/2019

Aprovado: 17/02/2019

Henyo T. Barretto Filho é Doutor em Antropologia Social (FFLCH/USP, 2001) e Professor Adjunto do Departamento de Antropologia da Universidade de Brasília, onde também colabora no Mestrado Profissional em Sustentabilidade junto a Povos e Terras Tradicionais do Centro de Desenvolvimento Sustentável. ORCID: 0000-0003-3845-9936 Contato: henyo.barretto@gmail.com

\section{Referências bibliográficas}

HEREDIA, Beatriz M. A. 1979. A Morada daVida: trabalho familiar entre pequenos produtores do nordeste do Brasil. Rio de Janeiro: Paz \& Terra.

1988. Formas de Dominação e Espaço Social: a modernização da agroindústria canavieira em Alagoas. São Paulo: Marco Zero; Brasília, DF: MCT/CNPq.

. 2005a. Um Antropólogo numa ONG: algumas reflexões sobre prática acadêmica e prática 
política. Revista de Ciências Sociais, v. 36, n. 1/2, pp. 89-96. [Republicado em SILVA, Glaucia (org.). Antropologia Extramuros: novas responsabilidades sociais e políticas dos antropólogos. Brasília: Paralelo 15, 2008. pp. 87-98.]

2005b. Ethos y Habitus en Antropología. Reflexiones a partir de una trayectoria. Avá Revista de Antropología (Universidad Nacional de Misiones, Argentina), n. 6, pp. 1-15. Disponível em: http://www.redalyc.org/articulo.oa?id= 169021465001 . 